\title{
Insufficiency of Cellular Energy (ICE) May Precede Neurodegeneration in Alzheimer's Disease and Be Treatable via the Alternative Cellular Energy (ACE) Pathway
}

\author{
W. John Martin \\ Institute of Progressive Medicine, South Pasadena, CA, USA \\ Email: wjohnmartin@ccid.org
}

How to cite this paper: Martin, W.J. (2017) Insufficiency of Cellular Energy (ICE) May Precede Neurodegeneration in Alzheimer's Disease and Be Treatable via the Alternative Cellular Energy (ACE) Pathway. Advances in Alzheimer's Disease, 6, 1-12.

https://doi.org/10.4236/aad.2017.61001

Received: January 5, 2017

Accepted: February 27, 2017

Published: March 2, 2017

Copyright $\odot 2017$ by author and Scientific Research Publishing Inc. This work is licensed under the Creative Commons Attribution-NonCommercial International License (CC BY-NC 4.0). http://creativecommons.org/licenses/by/4.0/ (c) (i) \& Open Access

\begin{abstract}
The term neurodegeneration emphasizes the destruction of neuronal cells as the primary explanation of many major neurological illnesses, including Alzheimer's disease. Specialized functioning of cells requires more cellular energy than is needed for basic cell survival. Cells can acquire energy both from the metabolism of food and from the alternative cellular energy (ACE) pathway. The ACE pathway is an added dynamic (kinetic) quality of the body's fluids occurring from the absorption of an external force termed KELEA (Kinetic Energy Limiting Electrostatic Attraction). KELEA is attracted to separated electrical charges and is seemingly partially released as the charges become more closely linked. As suggested elsewhere, the fluctuating electrical activity in the brain may attract KELEA from the environment and, thereby, contribute to the body's ACE pathway. Certain illnesses affecting the brain may impede this proposed antenna function of the brain, leading to a systemic insufficiency of cellular energy (ICE). Furthermore, individual neurons may derive some of the energy for their own activities from the repetitive depolarization of the cell. This may explain why hyper-excitability of neurons can occur in response to cell damage. This adaptive mechanism is unlikely to be sustainable, however, especially if there is a continuing need to synthesize neurotransmitters and membrane ion channels. The energy deficient neurons would then become quiescent and, although remaining viable, would not perform their intended specialized functions. Actual cell death would not necessarily occur till much later in the disease process. The distinction between quiescent and degenerated cells is important since the ACE pathway can be enhanced by several means, including the regular consumption of KELEA activated water. This, in turn, may improve the proposed antenna function of individual neurons, leading to a sustained restoration of specialized function via the ACE pathway. This paper
\end{abstract}


explores this novel concept and provides a rationale for clinical testing of KELEA activated water in patients with neurological and psychiatric illnesses, including Alzheimer's disease.

\section{Keywords}

Alzheimer's Disease, Alternative Cellular Energy, ACE, Insufficiency of Cellular Energy, ICE, Kinetic Energy Limiting Electrostatic Attraction, KELEA, Homeopathy, Enercel, Enerceutical, Calorie, Metabolism, Electrical Charge, Membrane Potential, Neurodegeneration, Psychiatry

\section{Introduction}

The ACE pathway was initially identified as providing a non-immunological defense mechanism against stealth adapted viruses [1]. These are derivative viruses, which have either lost or mutated the relatively few virus components normally targeted by the cellular immune system [2] [3] [4]. A cellular repair process occurs in the culturing of these viruses [1] [5]. It results from the production of chemical compounds, which typically self-assemble into particles and longer threads. These particulate materials are commonly pigmented, fluorescent, electrostatic, occasionally ferromagnetic and have electron donating, lipid synthesizing and water activating properties [1] [5]. The latter can be seen in the formation of vapor bubbles when the particles are placed into water [1] [5]. A striking feature of both in vivo and in vitro stealth adapted virus infected cells is the marked disruption of the cells' mitochondria (the main source of energy from the metabolism of food) [5]. Cellular survival in these cells is attributed to the energy transducing particulate materials, which are accordingly termed ACE pigments [1].

Refeeding of repaired stealth adapted virus infected cultures with fresh tissue culture medium leads to the rapid reactivation of the cytopathic effect (CPE). This can be prevented by adding ACE pigment particles to the refeeding medium [1] [5]. Inhibition of reactivation was also achieved using small amounts of a purportedly homeopathic remedy termed HANSI (Homeopathic Activator of the Natural System Immune). The demonstration of activity of HANSI in tissue cultures clearly excluded a direct role involving the immune system. Based on the ACE pathway concept, the United States manufacturer of HANSI renamed the product to Enercel.

The formulation of HANSI and the early productions of Enercel contained detectable levels of Lidocaine, a dipolar compound. Further studies on virus culture-derived ACE pigments and ACE pigments directly obtained from stealth adapted virus infected patients, led to studies showing that many dipolar chemicals can alter the physical and biophysical properties of water and other fluids [6] [7] [8]. The physical changes in water include the reduction in surface tension, increased volatility and more marked internal dynamic (kinetic) activity. 
These changes are attributed to a reduction in the hydrogen bonding between water molecules [9]. A more general principle has emerged that KELEA is a fundamental force required to prevent the fusion and possible annihilation of electrostatically attracted opposite electrical charges. It is seemingly attracted to the separated electrical charges on dipolar molecules. Certain dipolar molecules can release KELEA to nearby water, possibly in an oscillatory manner. Various electrical devices with rapid on-off switching or which repetitively propel opposite electrical charges towards one another can similarly lead to the activation of nearby water [10] [11] [12] [13].

\section{Separating and Rejoining Electrical Charges as a Source of Cellular Energy}

The membrane partitioning of hydrogen ions and its subsequent channeling back through the membrane provides the driving force allowing ATP synthase to add a third phosphate onto adenosine diphosphate (ADP) to form adenosine triphosphate (ATP) in both chlorophyll-mediated photosynthesis [14] and mitochondria-based food metabolism [15]. A reasonable question is where Nature initially derived the energy to form ATP synthase, chlorophyll, and the complex electron transferring molecules required for mitochondrial oxidative phosphorylation.

An intriguing possibility is that the membrane separation of electrical charges also allows for the attraction of KELEA, which could be partially released as the charges become more closely linked. KELEA could, thereby, provide a primary source of energy from which life has evolved. This process would likely be retained such that depolarization of the membrane potential of cells can act as an antenna to attract KELEA for transfer to both intracellular and extracellular water. This property would, therefore, be a basic energy-generating function of electrically excitable cells including neurons. The spontaneous electrical activity of the brain as reflected in the electroencephalogram (EEG) and in the oscillatory activities of various neurons may reflect the proposed antenna function of the brain in attracting KELEA into the body [16] [17] [18] [19]. The fluctuating electrical activities of muscles, including the heart, may similarly reflect KELEA attracting phenomena.

Support for the possibility that the body has an added energy-generating system is the realization that food metabolism is unlikely to totally provide the daily expenditure of energy by living organisms, including humans. Thus, for a $75 \mathrm{ki}$ logram $(\mathrm{Kg})$ individual to simply maintain body temperature at $20^{\circ} \mathrm{C}$ above the average environmental temperature requires 1500 Calories $(75 \times 20)$. Since the body heat dissipates in less than 24 hours after death, these 1500 Calories are required daily. A typical diet of approximately 2000 Calories per day would leave insufficient Calories to reasonably account for skeletal muscle, cardiovascular, brain, liver and other physiological functions [20].

Additional support for the concept that the brain may have direct water activating capacity has come from observations on water samples placed within a 
room of individuals participating in a laughing yoga class. These samples became more volatile, which is a measure of water activation, than did control samples not placed within the room [21]. The author has also encountered individuals with the ability to directly energize nearby water. They do so by adopting mental states, which they have individually found to be effective. This suggests that if indeed the brain is a major antenna for KELEA, then it is a variable property that can potentially be learned [20].

The ACE pathway provides more than just an addition to the energy derived from food metabolism. Specifically, it enhances resistance to infectious illnesses, having several advantages when compared to the immune system [22]. The ACE pathway may be able to bypass the metabolic blockades presumably preventing apoptosis in some tumors [23]. Ongoing clinical studies are highly suggestive of the ACE pathway contributing to functional activities of the brain that are not directly supported by food metabolism.

\section{Insufficiency of Cellular Energy (ICE)}

Neuronal cells can become deficient in cellular energy if their capacity to generate ATP from food metabolism is limiting. This can occur from reduced blood supply of nutrients and/or oxygen, along with an inability to effectively remove carbon dioxide, urea, and other metabolic waste products. Cellular energy deficiency can also arise from intrinsic defects in various metabolic pathways. These defects can be primarily genetic or secondary to external factors, including toxins and microbes. The normal functioning of neuronal cells is presumably also dependent upon the ACE pathway as it exists throughout the body. Individual neurons may also depend upon locally generated KELEA resulting from their own repetitive depolarization.

Establishing the membrane potential in most cell types, including neurons, requires the active transport of sodium $\left(\mathrm{Na}^{+}\right)$ions from within the cell to the extracellular space. The same transporter imports one-third less potassium $\left(\mathrm{K}^{+}\right)$ ions into the cell [24]. Depolarization with the formation of an action potential occurs by an induced major influx of $\mathrm{Na}^{+}$ions into the cell. The inflowing $\mathrm{Na}^{+}$ ions must then be secreted from the cell to repolarize the cell membrane. The $\mathrm{Na} / \mathrm{K}$ transporter utilizes ATP as an energy source. Depolarization/repolarization, therefore, requires ongoing chemical energy [25]. It is proposed that some of this energy usage may be offset by, or at least essentially exchanged for the delivery of KELEA into the cell.

This energy gathering process is likely to be far more efficient for depolarizations occurring in unicellular organisms than for multicellular organisms with a networking nervous system. This is because the synthesis, secretion and reuptake of neurotransmitters at synaptic junctions add to the energy output of neuronal activity. Indeed, synaptic impulse transmissions utilize more ATP than does the generation of action potentials [26] [27] [28] [29] [30]. Actual studies on brain metabolism indicate that neuronal activities impose a significant drain on cellular metabolism. Still, if depolarization of unicellular organisms is an 
evolutionarily net source of cellular energy, then more frequent depolarization may have persisted as a cellular adaptation of electrically excitable cells, including neurons, to ICE.

The full opening of the $\mathrm{Na}^{+}$channel is triggered at a threshold level that requires sufficient reduction in the differential electrical charge across the membrane. The electrical charge on the inner side of the resting cell membrane is approximately -70 millivolts $(\mathrm{mV})$ with respect to the outside of the cell membrane. The $\mathrm{Na}^{+}$input channel is triggered at approximately $-50 \mathrm{mV}$. Thus, a lessening of the membrane potential, for example from $-70 \mathrm{mV}$ to $-60 \mathrm{mV}$, will lead to depolarization in response to minor stimuli that are unable to trigger cells with a normal membrane potential. Indeed, a lowered differential electrical charge is an early characteristic of neuronal cell damage [31] and by inference neuronal hyperactivity may be expected as an early manifestation of ICE.

As suggested above, repeated depolarization of a neuro-networking brain is a drain on the brain's cellular energy. In addition to the chemical energy demands of synaptic transmission, continuing hyperactivity appears to increase the turnover of ion channels. These channels are heavily glycosylated molecules and, therefore, cannot be readily brought back into the cell for recycling. If activation increases their turnover, then cellular energy will be required to maintain adequate numbers of ion channels within the external cell membrane [32]. The loss of ion channels would reduce ACE pathway input. The energy deficient neuronal cells would then enter a quiescent, survival mode of existence.

The progressive loss of cellular energy will eventually lead to cellular death and true neurodegeneration. This may, however, be a much latter phase of many neurological illnesses than is commonly envisioned. This reasoning applies to Alzheimer's disease, amyotrophic lateral sclerosis (ALS), Parkinson's disease and even aging.

\section{Alzheimer's Disease}

The underlying cause of Alzheimer's disease is still unknown. Genetic factors play a major role as does advancing age [33]. Overproduction of phosphorylated tau protein and both the overproduction and aberrant enzymatic cleavage of amyloid precursor protein (APP) occur in Alzheimer's disease patients [34]. Direct cellular toxicity has been attributed to both tau and amyloid-derived compounds, although efforts to reduce their levels have not shown major clinical benefits [35] [36]. As discussed elsewhere, it is feasible that neuronal cell damage leading to the overproduction of these materials may also occur from underlying stealth adapted virus infections. The notable accumulation of these materials in the brains of Alzheimer's disease patients, but not in younger stealth adapted virus infected patients, may be related to age-related inefficiency of a basic clearance mechanism [37].

Relevant to this paper are indications of possible hyperactivity within regions of the brain, including the hippocampus and motor cortex, as an early feature in Alzheimer's disease [38] [39] [40] [41] [42]. Neuronal hyperactivity in cognitive 
pathways may contribute to dementia by distracting from the comprehension and interpretation of specific thought processes. Patients with Alzheimer's disease commonly display positive psychiatric symptoms, such as delusions, hallucinations, and agitation [43] [44]. Although potentially attributed to a loss of inhibitory neurons, these symptoms are consistent with intrinsic neuronal hyperactivity. The occurrence of new-onset epilepsy in conjunction with Alzheimer's disease [45] [46] [47] is also consistent with an initial hyperactivity phase of the illness.

Alzheimer's disease patients progress to illnesses in which there is clear hypofunctioning of multiple regions of the brain. The neurological deficits extend beyond impaired cognition in patients with advanced Alzheimer's disease. Most patients exhibit emotional apathy, social withdrawal, depression, blurred speech, impaired hearing, loss of smell, autonomic dysfunction, delayed reflexes, and poorly coordinated muscle activity [48] [49] [50] [51] [52]. Although the loss of neuronal cells can be demonstrated histologically, the signs and symptoms are not necessarily entirely due to neuronal degeneration. Rather, there may also be a major component of neuronal cells simply failing to engage in their intended specialized functions.

\section{Clinical Improvements in Alzheimer's Disease Patients}

Improvements resulting from lifestyle interventions have been observed in several Alzheimer's disease patients. The interventions primarily involve changes in diet, reduction of stress levels and/or increased aerobic exercise. This is still a controversial topic with some neurologists suggesting that significant reductions in symptoms preclude the earlier clinical diagnosis of Alzheimer's disease. Nevertheless, clinical improvements are consistent with neuronal cell dysfunction, as opposed to irreversible cellular degeneration. The dietary changes include switching to either a ketogenic [53] or a Mediterranean diet [54] usually in addition to consuming various dietary supplements. The common dietary supplements include medium chain triglycerides; phosphatidylcholine and other membrane lipids; Moringa oleifera; turmeric; cocoa; niacin; and others [55]-[62]. A trusted colleague has told me that she has achieved consistent cognitive improvements in well over fifty elderly Alzheimer's patients during the last several years. Her therapies include the regular consumption of water containing sodium chloridedepleted minerals from the Great Salt Lake, other dietary supplements and having her patients adopt an optimistic, mindfulness, mental attitude. Most alternative medical practitioners are likely to attribute any apparent clinical benefits of dietary supplements either to an assumed anti-oxidant activity or to the correcting of supposed underlying nutrient or mineral deficiencies [62]. KELEA is absorbed by dipolar chemicals and it can be argued, that the reported beneficial dietary compounds act by increasing the supply of KELEA to the body [7]. The term Enerceutical has been suggested for compounds with KELEA attracting and water activating properties [7]. It is further possible that even the willingness to make dietary changes reflects a basic change in brain activity, which may co- 
incidentally enhance its KELEA antenna function. Similarly, the decision to minimize stress or to engage in more vigorous exercising may be shown in future clinical trials to increase the brain's KELEA absorbing capacity.

\section{Controlled Studies on Enhancing the ACE Pathway}

There are multiple ways to activate the ACE pathway and some are particularly well suited to double-blinded clinical trials. Among the more informative trials are the direct comparisons between matched groups of patients consuming either KELEA activated or regular water. Sufficient water activation for initial clinical studies can be provided by simply placing water into KELEA concentrating energy fields, as can be achieved by opposing fluctuating lights [12] and by other methods. Another approach is to use dipolar herbal components with subsequent, repeated dilutions to essentially reduce the residual concentrations to below detectable levels [63]. One study showed remarkable benefits of injecting and inhaling Enercel in tuberculosis-infected AIDS patients [64]. A striking feature of the study was the improved mood and cognition that occurred in addition to the clearance of the mycobacteria and the reduction in HIV levels. Current test protocols in this and other medical conditions now involve the drinking of approximately $500 \mathrm{ml}$ per day of KELEA activated versus control water. Employing yet another protocol to enhance the ACE pathway, the healing of herpes virus infections has been expedited [65]. ACE pathway activation has clinically helped children with autism, including leading to the permanent suppression of epilepsy in a child [66].

\section{Conclusion}

This paper provides the rationale for clinical studies on the possible therapeutic value of activated water in patients with Alzheimer's disease. A major premise of the paper is that cells can acquire cellular energy via the alternative cellular energy (ACE) pathway. It is expressed as an added kinetic (dynamic) activity of the intracellular and extracellular fluids within the body. The energy for the ACE pathway comes from the absorption of a natural environmental force termed KELEA (Kinetic Energy Limiting Electrostatic Attraction). It is proposed that unlike most other cell types, neuronal cells may be able to directly attract KELEA from the external environment during their electrical depolarization. Indeed, repetitive depolarization may be an initial adaptive response of neuronal cells to an insufficiency of cellular energy (ICE). The damaged neuronal cells may progress to become hypo-responsive, quiescent cells [67]. As such, although still viable, the neurons would be unable to perform their intended more specialized functions. KELEA can be transferred into water for drinking and consuming KELEA activated water can be compared with consuming regular water for possible therapeutic benefits in patients with various neurological illnesses, including Alzheimer's disease. Clinical efficacy in such studies will naturally lead to major efforts at disease prevention through the support of the ACE pathway. 


\section{Acknowledgements}

The Institute of Progressive Medicine is a component of MI Hope Inc., a nonprofit public charity. Valuable clinical input and insights have been received from various Complementary and Alternative Medicine practitioners.

\section{References}

[1] Martin, W.J. (2003) Stealth Virus Culture Pigments: A Potential Source of Cellular Energy. Experimental and Molecular Pathology, 74, 210-223. https://doi.org/10.1016/S0014-4800(03)00037-6

[2] Martin, W.J. (1994) Stealth Viruses as Neuropathogens. College of American Pathologist's Publication, CAP Today, 8, 67-70.

[3] Martin, W.J., Zeng, L.C., Ahmed, K. and Roy, M. (1994) Cytomegalovirus Related Sequences in an Atypical Cytopathic Virus Repeatedly Isolated from a Patient with the Chronic Fatigue Syndrome. American Journal Pathology, 145, 440-451.

[4] Martin, W.J. (2014) Stealth Adaptation of Viruses: Review and Updated Molecular Analysis on a Stealth Adapted African Green Monkey Simian Cytomegalovirus (SCMV). Journal of Human Virology and Retrovirology, 1, Article ID: 00020. https://doi.org/10.15406/jhvrv.2014.01.00020

[5] Martin, W.J. (2014) The Alternative Cellular Energy (ACE) Pathway in the Repair of the Cytopathic Effect (CPE) Caused by Stealth Adapted Viruses. In Vitro and in Vivo Evidence Supporting a New Therapeutic Paradigm. In Stealth Adapted Viruses; Alternative Cellular Energy (ACE) \& KELEA Activated Water. Author House Bloomington, IN, 31-70.

[6] Martin, W.J. (2015) Therapeutic Potential of KELEA Activated Water. International Journal of Complementary and Alternative Medicine, 1, Article ID: 00001. https://doi.org/10.15406/ijcam.2015.01.00001

[7] Martin, W.J. (2015) Alternative Cellular Energy Pathway Therapy Using KELEA Activated Water. International Journal of Complementary and Alternative Medicine, 2, Article ID: 00051. https://doi.org/10.15406/ijcam.2015.02.00051

[8] Martin, W.J. (2015) KELEA Activation of Water and Other Fluids for Health, Agriculture and Industry. Journal of Water Resource and Protection, 7, 1331-1344. https://doi.org/10.4236/jwarp.2015.716108

[9] Martin, W.J. (2015) KELEA: A Natural Energy That Seemingly Reduces Intermolecular Hydrogen Bonding in Water and Other Liquids. Open Journal of Biophysics, 5, 69-79. https://doi.org/10.4236/ojbiphy.2015.53006

[10] Martin, W.J. (2016) KELEA (Kinetic Energy Limiting Electrostatic Attraction) Offers an Alternative Explanation to Existing Concepts Regarding Wave-Particle Duality, Cold Fusion and Superconductivity. Journal of Modern Physics, 7, 1995-2007. https://doi.org/10.4236/jmp.2016.715176

[11] Martin, W.J. (2015) Preparing and Using KELEA Activated Water to Enhance the Alternative Cellular Energy (ACE) Pathway in the Therapy of Multiple Illnesses. International Journal Complementary \& Alternative Medicine, 3, Article ID: 00059.

[12] Martin, W.J. (2015) Interacting Light Paths Attract KELEA (Kinetic Energy Limiting Electrostatic Attraction) and Can Lead to the Activation of Water. Open Journal of Biophysics, 5, 115-121. https://doi.org/10.4236/ojbiphy.2015.54010

[13] Martin, W.J. (2015) Interactive Electric Fields Attract KELEA (Kinetic Energy Limiting Electrostatic Attraction) and Can Lead to the Activation of Water. International Journal Complementary Alternative Medicine, 1, Article ID: 00034. 
[14] Pessarakli, M. (2016) Handbook of Photosynthesis. 3rd Edition, CRC Press, Boca Raton, 846. https://doi.org/10.1201/b19498

[15] Smeitink, J.A.M. (2007) Oxidative Phosphorylation in Health and Disease. Springer Publishing, New York, 205.

[16] Barlow, J.S. (1993) The Electroencephalogram, Its Patterns and Origins. MIT Press, Cambridge, 456.

[17] Fox, M.D. and Raichle, M.E. (2007) Spontaneous Fluctuations in Brain Activity Observed with Functional Magnetic Resonance Imaging. Nature Reviews Neuroscience, 8, 700-711. https://doi.org/10.1038/nrn2201

[18] Llinás, R.R., Grace, A.A. and Yarom, Y. (1991) In Vitro Neurons in Mammalian Cortical Layer 4 Exhibit Intrinsic Oscillatory Activity in the 10- to 50-Hz Frequency Range. Proceedings of the National Academy of Sciences of the United States of America, 88, 897-901. https://doi.org/10.1073/pnas.88.3.897

[19] Moore, A.R., Zhou, W.-L., Jakovcevski, I., Zecevic, N. and Antic, S.D. (2011) Spontaneous Electrical Activity in the Human Fetal Cortex in Vitro. Journal of Neuroscience, 31, 2391-2398. https://doi.org/10.1523/JNEUROSCI.3886-10.2011

[20] Martin, W.J. (2014) KELEA Activated Water-Enhancing the Alternative Cellular Energy (ACE) Pathway. In: Martin, W.J., Ed., Stealth Adapted Viruses, Alternative Cellular Energy (ACE) \& KELEA Activated Water, AuthorHouse, Bloomington, 115-144.

[21] Martin, W.J. (2015) Is the Brain an Activator of the Alternative Cellular Energy (ACE) Pathway? International Journal Complementary Alternative Medicine, 1, Article ID: 00002. https://doi.org/10.15406/ijcam.2015.01.00002

[22] Martin, W.J. (2016) The Alternative Cellular Energy (ACE) Pathway as a Primary Non-Immunological Defense Mechanism Against Infectious Diseases. Juniper Online Journal of Immuno Virology, 1, Article ID: 555563.

[23] Martin, W.J. (2016) Cancer as an Insufficiency of Cellular Energy (ICE), Therapeutic Approaches Based on Enhancing the Alternative Cellular Energy (ACE) Pathway. International Journal Complementary Alternative Medicine, 3, Article ID: 00074. https://doi.org/10.15406/ijcam.2016.03.00074

[24] Kaplan, J.H. (2002) Biochemistry of Na, K-ATPase. Annual Review of Biochemistry, 71, 511-535. https://doi.org/10.1146/annurev.biochem.71.102201.141218

[25] Astrup, J., Sørensen, P.M. and Sørensen, H.R. (1981) Oxygen and Glucose Consumption Related to Na+-K+ Transport in Canine Brain. Stroke, 12, 726-730. https://doi.org/10.1161/01.STR.12.6.726

[26] Martonosi, A.N. (2012) Membranes and Transport. Springer Publishing, New York, 722.

[27] Wang, R., Tsuda, I. and Zhang, Z. (2015) A New Work Mechanism on Neuronal Activity. International Journal of Neural Systems, 25, Article ID: 1450037. https://doi.org/10.1142/s0129065714500373

[28] Ames, A. (2000) CNS Energy Metabolism as Related to Function. Brain Research Reviews, 34, 42-68. https://doi.org/10.1016/S0165-0173(00)00038-2

[29] Attwell, D. and Laughlin, S.B. (2001) An Energy Budget for Signaling in the Grey Matter of the Brain. Journal of Cerebral Blood Flow \& Metabolism, 21, 1133-1145. https://doi.org/10.1097/00004647-200110000-00001

[30] Niven, J.E. (2016) Neuronal Energy Consumption, Biophysics, Efficiency and Evolution. Current Opinion in Neurobiology, 41,129-135. https://doi.org/10.1016/j.conb.2016.09.004

[31] Lirk, P., Poroli, M., Rigaud, M., Fuchs, A., Fillip, P., Huang, C.-Y., et al. (2008) Mo- 
dulators of Calcium Influx Regulate Membrane Excitability in Rat Dorsal Root Ganglion Neurons. Anesthesia Analgesia, 107, 673-685.

https://doi.org/10.1213/ane.0b013e31817b7a73

[32] Ednie, A.R. and Bennett, E.S. (2012) Modulation of Voltage-Gated Ion Channels by Sialylation. Comprehensive Physiology, 2, 1269-301.

https://doi.org/10.1002/cphy.c110044

[33] Hollingworth, P., Harold, D., Jones, L., Owen, M.J. and Williams, J. (2011) Alzheimer's Disease Genetics, Current Knowledge and Future Challenges. International Journal Geriatric Psychiatry, 26, 793-802. https://doi.org/10.1002/gps.2628

[34] Lehmann, S. and Teunissen, C.E. (2016) Biomarkers of Alzheimer's Disease, the Present and the Future. Frontiers Media, Lausanne, 213.

https://doi.org/10.3389/978-2-88945-041-1

[35] Drachman, D.A. (2014) The Amyloid Hypothesis, Time to Move on, Amyloid Is the Downstream Result, Not Cause, of Alzheimer's Disease. Alzheimer's Dement, 10, 372-380. https://doi.org/10.1016/j.jalz.2013.11.003

[36] Herrup, K. (2015) The Case for Rejecting the Amyloid Cascade Hypothesis. Nature Neuroscience, 18, 794-799. https://doi.org/10.1038/nn.4017

[37] Martin, W.J. (2015) Stealth Adapted Viruses-Possible Drivers of Major Neuropsychiatric Illnesses Including Alzheimer's Disease. Journal of Neurology \& Stroke, 2, Article ID: 00057. https://doi.org/10.15406/jnsk.2015.02.00057

[38] Busche, M.A. and Konnerth, A. (2015) Neuronal Hyperactivity-A Key Defect in Alzheimer's Disease? Bioessays, 37, 624-632. https://doi.org/10.1002/bies.201500004

[39] Stargardt, A., Swaab, D.F. and Bossers, K. (2015) The Storm before the Quiet, Neuronal Hyperactivity and $\mathrm{A} B$ in the Presymptomatic Stages of Alzheimer's Disease. Neurobiology of Aging, 36, 1-11.

https://doi.org/10.1016/j.neurobiolaging.2014.08.014

[40] Dickerson, B.C., Salat, D.H., Greve, D.N., Chua, E.F., Rand-Giovannetti, E., Rentz, D.M., et al. (2005) Increased Hippocampal Activation in Mild Cognitive Impairment Compared to Normal Aging and AD. Neurology, 65, 404-411. https://doi.org/10.1212/01.wnl.0000171450.97464.49

[41] Bakker, A., Krauss, G.L., Albert, M.S., Speck, C.L., Jones, L.R., Stark, C.E., et al. (2012) Reduction of Hippocampal Hyperactivity Improves Cognition in Amnestic Mild Cognitive Impairment. Neuron, 74, 467-474. https://doi.org/10.1016/j.neuron.2012.03.023

[42] Albers, M.W., Gilmore, G.C., Kaye, J., Murphy, C., Wingfield, A., Bennett, D.A., et al. (2015) At the Interface of Sensory and Motor Dysfunctions and Alzheimer's Disease. Alzheimer's \& Dementia, 11, 70-98. https://doi.org/10.1016/j.jalz.2014.04.514

[43] Lyketsos, C.G., Carrillo, M.C., Ryan, J.M., Khachaturian, A.S., Trzepacz, P., Amatniek, J., et al. (2011) Neuropsychiatric Symptoms in Alzheimer's Disease. Alzheimer's \& Dementia, 7, 532-539. https://doi.org/10.1016/j.jalz.2011.05.2410

[44] Zhao, Q.-F., Tan, L., Wang, H.-F., Jiang, T., Tan, M.-S., Tan, L., et al. (2016) The Prevalence of Neuropsychiatric Symptoms in Alzheimer's Disease, Systematic Review and Meta-Analysis. Journal of Affective Disorders, 190, 264-271. https://doi.org/10.1016/j.jad.2015.09.069

[45] Irizarry, M.C., Jin, S., He, F., Emond, J.A., Raman, R., Thomas, R.G., et al. (2012) Incidence of New-Onset Seizures in Mild to Moderate Alzheimer Disease. Archives of Neurology, 69, 368-372. https://doi.org/10.1001/archneurol.2011.830

[46] Bom, H.A. (2014) Seizures in Alzheimer's Disease. Neuroscience, 286, 251-263.

[47] Vossel, K.A., Beagle, A.J., Rabinovici, G.D., Shu, H., Lee, S.E., Naasan, G., et al. 
(2013) Seizures and Epileptiform Activity in the Early Stages of Alzheimer Disease. JAMA Neurology, 70, 1158-1166. https://doi.org/10.1001/jamaneurol.2013.136

[48] Gates, G.A., Anderson, M.L., Feeney, M.P., McCurry, S.M. and Larson, E.B. (2008) Central Auditory Dysfunction in Older Persons with Memory Impairment or Alzheimer Dementia. Archives of Otolaryngology_Head and Neck Surgery, 134, 771777. https://doi.org/10.1001/archotol.134.7.771

[49] Murphy, C., Gilmore, M.M., Seery, C.S., Salmon, D.P. and Lasker, B.R. (1990) Olfactory Thresholds are Associated with Degree of Dementia in Alzheimer's Disease. Neurobiology of Aging, 11, 465-469. https://doi.org/10.1016/0197-4580(90)90014-Q

[50] Pache, M., Smeets, C.H., Gasio, P.F., Savaskan, E., Flammer, J., Wirz-Justice, A., et al. (2003) Colour Vision Deficiencies in Alzheimer's Disease. Age Ageing, 32, 422 426. https://doi.org/10.1093/ageing/32.4.422

[51] Rizzo, M., Anderson, S.W., Dawson, J. and Nawrot, M. (2000) Vision and Cognition in Alzheimer's Disease. Neuropsychologia, 38, 1157-1169. https://doi.org/10.1016/S0028-3932(00)00023-3

[52] Femminella, G.D., Rengo, G., Komici, K., Iacotucci, P., Petraglia, L., Pagano, G., et al. (2014) Autonomic Dysfunction in Alzheimer's Disease, Tools for Assessment and Review of the Literature. Journal of Alzheimer's Disease, 42, 369-377.

[53] Lange, K.W., Katharina, M., Lange, K.M., Makulska-Gertruda, E., Nakamura, Y., Reissmann, A., et al. (2016) Ketogenic Diets and Alzheimer's Disease. Food Science and Human Wellness, in Press. https://doi.org/10.1016/j.fshw.2016.10.003

[54] Frisardi, V., Panza, F., Seripa, D., Imbimbo, B.P., Vendemiale, G., Pilotto, A., et al. (2010) Nutraceutical Properties of Mediterranean Diet and Cognitive Decline, Possible Underlying Mechanisms. Journal of Alzheimer's Disease, 22, 715-740.

[55] Solfrizzi, V., Panza, F., Frisardi, V., Seripa, D., Logroscino, G., Imbimbo, B.P., et al. (2011) Diet and Alzheimer's Disease Risk Factors or Prevention, the Current Evidence. Expert Review of Neurotherapeutics, 11, 677-708. https://doi.org/10.1586/ern.11.56

[56] Hügel, H.M. (2015) Brain Food for Alzheimer-Free Ageing, Focus on Herbal Medicines. Advances in Experimental Medicine and Biology, 863, 95-116. https://doi.org/10.1007/978-3-319-18365-7_5

[57] Cernacchi, T., Bertoldin, T., Farina, C., Flori, M.G. and Crepaldi, G. (1993) Cognitive Decline in the Elderly, a Double-Blind, Placebo-Controlled Multicenter Study on the Efficacy of Phosphatidylserine Administration. Aging, 5, 123-133.

[58] Nicolson, G. (2016) Clinical Uses of Membrane Lipid Replacement Supplements in Restoring Membrane Function and Reducing Fatigue in Chronic Diseases and Cancer. Discoveries, 4, e54. https://doi.org/10.15190/d.2016.1

[59] Obulesu, M. and Rao, D.M. (2011) Effect of Plant Extracts on Alzheimer's Disease, an Insight into Therapeutic Avenues. Journal of Neurosciences in Rural Practice, 2 , 56-61. https://doi.org/10.4103/0976-3147.80102

[60] Morris, M.C., Evans, D.A., Bienias, J.L., Scherr, P.A., Tangney, C.C., Hebert, L.E., et al. (2004) Dietary Niacin and the Risk of Incident Alzheimer's Disease and of Cognitive Decline. Journal of Neurology, Neurosurgery \& Psychiatry, 75, 1093-1099. https://doi.org/10.1136/jnnp.2003.025858

[61] Dubner, L., Wang, J., Ho, L., Ward, L. and Pasinetti, G.M. (2015) Recommendations for Development of New Standardized Forms of Cocoa Breeds and Cocoa Extract Processing for the Prevention of Alzheimer's Disease, Role of Cocoa in Promotion of Cognitive Resilience and Healthy Brain Aging. Journal of Alzheimer's Disease, 48, 879-889. https://doi.org/10.3233/JAD-150536 
[62] Kamphuis, P.J. and Scheltens, P. (2010) Can Nutrients Prevent or Delay Onset of Alzheimer's Disease? Journal of Alzheimer's Disease, 20, 765-775.

[63] Martin, W.J. and Laurent, D. (2015) Homeopathy as a Misnomer for Activation of the Alternative Cellular Energy Pathway, Evidence for the Therapeutic Benefits of Enercel in a Diverse Range of Clinical Illnesses. International Journal Complementary Alternative Medicine, 2, Article ID: 00045. https://doi.org/10.15406/ijcam.2015.02.00045

[64] Dubrov, V., Dubrova, T., Christner, D., Laurent, D. and Martin, W.J. (2015) Alternative Cellular Energy Based Therapy Using Enercel in Advanced AIDS Patients Co-Infected with Tuberculosis and Treated in Chernigov, Ukraine. Journal Human Virology Retrovirology, 2, Article ID: 00061.

[65] Martin, W.J. and Stoneburner, J. (2005) Symptomatic Relief of Herpetic Skin Lesions Utilizing an Energy Based Approach to Healing. Experimental Molecular Pathology, 78, 131-134. https://doi.org/10.1016/j.yexmp.2004.10.007

[66] Martin, W.J. (2014) Alternative Cellular Energy (ACE) Pathway Activation as Natural Therapy for Autism. In: Martin, W.J., Ed., Stealth Adapted Viruses, Alternative Cellular Energy (ACE) \& KELEA Activated Water, AuthorHouse, Bloomington, 87102.

[67] Martin, W.J. (2016) Insufficiency of Cellular Energy (ICE) in Neurons, From Electrical Hyperactivity to Quiescence. International Journal Complementary Alternative Medicine, 4, Article ID: 00118.

\section{Abbreviations}

ACE alternative cellular energy

ICE insufficiency of cellular energy

KELEA kinetic energy limiting electrostatic attraction

ATP adenosine triphosphate

ADP adenosine diphosphate

$\mathrm{Na}^{+} \quad$ sodium ion

$\mathrm{K}^{+} \quad$ potassium ion

$\mathrm{mV} \quad$ millivolt

Kg kilogram 
Submit or recommend next manuscript to SCIRP and we will provide best service for you:

Accepting pre-submission inquiries through Email, Facebook, LinkedIn, Twitter, etc. A wide selection of journals (inclusive of 9 subjects, more than 200 journals)

Providing 24-hour high-quality service

User-friendly online submission system

Fair and swift peer-review system

Efficient typesetting and proofreading procedure

Display of the result of downloads and visits, as well as the number of cited articles Maximum dissemination of your research work

Submit your manuscript at: http://papersubmission.scirp.org/

Or contact aad@scirp.org 